This is the author's final, peer-reviewed manuscript as accepted for publication. The publisher-formatted version may be available through the publisher's web site or your institution's library.

\title{
The effects of dietary fish oil on exercising skeletal muscle vascular and metabolic control in chronic heart failure rats
}

Clark T. Holdsworth, Steven W. Copp, Daniel M. Hirai, Scott K. Ferguson, Gabrielle E. Sims, Karen S. Hageman, Charles L. Stebbins, David C. Poole and Timothy I. Musch

\section{How to cite this manuscript}

If you make reference to this version of the manuscript, use the following information:

Holdsworth, C. T., Copp, S. W., Hirai, D. M., Ferguson, S. K., Sims, G. E., Hageman, K. S., Stebbins, C. L., Poole, D. C., \& Musch, T. I. (2014). The effects of dietary fish oil on exercising skeletal muscle vascular and metabolic control in chronic heart failure rats.

\section{Published Version Information}

Citation: Holdsworth, C. T., Copp, S. W., Hirai, D. M., Ferguson, S. K., Sims, G. E., Hageman, K. S., Stebbins, C. L., Poole, D. C., \& Musch, T. I. (2014). The effects of dietary fish oil on exercising skeletal muscle vascular and metabolic control in chronic heart failure rats. Applied Physiology, Nutrition and Metabolism, 39(3), 299-307.

Digital Object Identifier (DOI): 10.1139/apnm-2013-0301

Publisher's Link: http://www.nrcresearchpress.com/doi/full/10.1139/apnm-20130301\#.VH9EI5XF-4I 
Acute blockade of ATP-sensitive $\mathrm{K}^{+}$channels impairs skeletal muscle vascular control in rats during treadmill exercise

Clark T. Holdsworth ${ }^{1}$, Steven W. Copp ${ }^{1}$, Scott K. Ferguson ${ }^{1}$, Gabrielle E. Sims ${ }^{2}$, David C. Poole $^{1,2}$, Timothy I. Musch ${ }^{1,2}$

${ }^{1}$ Department of Anatomy and Physiology, ${ }^{2}$ Department of Kinesiology, Kansas State University, Manhattan, KS, 66506, USA

Running title: ATP-sensitive $\mathrm{K}^{+}$channels and vascular control

Total words: 5686

Key Words: blood flow, conductance, glibenclamide

Corresponding author: Clark T. Holdsworth

228 Coles Hall

Department of Anatomy and Physiology

College of Veterinary Medicine

Kansas State University

Manhattan, KS 66506-5802

Tel.: 607-743-5805, e-mail: clark40@k-state.edu 


\section{Key points}

- The ATP-sensitive $\mathrm{K}^{+}\left(\mathrm{K}_{\mathrm{ATP}}\right)$ channel is activated, in part, by reductions in the ratio of ATP-to-ADP and may therefore contribute to the integration of cellular metabolism with vasomotor tone.

- The impact of $\mathrm{K}_{\mathrm{ATP}}$ channels on exercising skeletal muscle blood flow (BF) may be dependent upon whether the metabolic demand elicits a sufficiently low $\mathrm{O}_{2}$ tension to drive ADP accumulation and open $\mathrm{K}_{\mathrm{ATP}}$ channels.

- Rats performed treadmill exercise (20 $\mathrm{m} \mathrm{min}^{-1}, 5 \%$ incline) for the determination of $\mathrm{BF}$ and vascular conductance (VC) before and after $\mathrm{K}_{\mathrm{ATP}}$ channel blockade via glibenclamide.

- $\mathrm{K}_{\mathrm{ATP}}$ channel blockade reduced exercising skeletal muscle BF and VC in a fibre type-selective manner and increased arterial blood [lactate].

- These data suggest that although the VC response to exercise relies on potentially redundant mechanisms $\mathrm{K}_{\mathrm{ATP}}$ channel function is requisite for healthy, large muscle mass exercise hyperaemia in rats. 


\begin{abstract}
The ATP-sensitive $\mathrm{K}^{+}\left(\mathrm{K}_{\mathrm{ATP}}\right)$ channel is a class of inward rectifier $\mathrm{K}^{+}$channels that can link cellular metabolic status to vasomotor tone across the metabolic transients seen with exercise. This investigation tested the hypothesis that if $\mathrm{K}_{\mathrm{ATP}}$ channels are crucial to exercise hyperaemia then blockade via glibenclamide (GLI) would lower hindlimb skeletal muscle blood flow (BF) and vascular conductance (VC) during treadmill exercise. In 14 adult male Sprague Dawley rats mean arterial pressure (MAP), blood [lactate], and hindlimb muscle BF (radiolabelled microspheres) were determined at rest $(n=6)$ or during exercise ( $n=8 ; 20 \mathrm{~m} \mathrm{~min}^{-1}, 5 \%$ incline) under control (CON) and GLI conditions (5 mg kg1 , i.a). At rest and during exercise, MAP was higher (Rest, CON: $130 \pm 6$, GLI: $152 \pm 8$; Exercise, CON: $140 \pm 4$, GLI: $147 \pm 4 \mathrm{mmHg}, P<0.05)$ and heart rate (HR) was lower (Rest, CON: $440 \pm$ 16, GLI: $410 \pm$ 18; Exercise, CON: $560 \pm$ 4, GLI: $540 \pm 10$ beats min ${ }^{-1}$, $P<0.05)$ with GLI. Hindlimb muscle BF (CON: $144 \pm 10$, GLI: $120 \pm 9 \mathrm{ml} \mathrm{min}^{-1}(100 \mathrm{~g})^{-1}$, $P<0.05$ ) and VC were lower with GLI during exercise but not at rest. Specifically, GLI decreased BF in 12, and VC in 16, of the 28 individual hindlimb muscles and muscle parts sampled during exercise with a greater fractional reduction present in muscles comprised predominantly of type I and type IIa fibres $(P<0.05)$. Additionally, blood [lactate] (CON: $2.0 \pm 0.3$; GLI: $\left.4.1 \pm 0.9 \mathrm{mmol} \mathrm{L}^{-1}, P<0.05\right)$ was higher during exercise with GLI. That $\mathrm{K}_{\mathrm{ATP}}$ channel blockade reduces hindlimb muscle BF during exercise in rats supports the obligatory contribution of $\mathrm{K}_{\mathrm{ATP}}$ channels in large muscle mass exercise-induced hyperaemia.
\end{abstract}




\section{Abbreviations}

BF, blood flow; CON, control; GLI, glibenclamide; HR, heart rate; $\mathrm{K}_{\mathrm{ATP}}$, ATP-sensitive potassium channel; Kir, inward rectifier potassium channels; $K_{N D P}$, nucleotide-dependent potassium channel; MAP, mean arterial pressure; SMC, smooth muscle cell; SNA, sympathetic nerve activity; VC, vascular conductance 
Introduction

Fundamental to cardiovascular control during exercise is an elevated sympathetic nerve activity (SNA) which increases heart rate (HR), stroke volume and therefore cardiac output. Appropriate redistribution of the increased cardiac output at exercise onset is achieved by vascular smooth muscle cell (SMC) relaxation in arterioles supplying active skeletal muscle and SMC contraction in arterioles supplying quiescent tissue. Accordingly, the elevation in SNA which drives cardiac output also precipitates increased vascular resistance in skeletal muscle via activation of $\alpha_{2}$-adrenergic receptors (Thomas and Segal 2004). Within the active skeletal muscle vascular bed, local metabolic byproducts of muscle contraction (e.g. ATP, $\mathrm{H}^{+}, \mathrm{K}^{+}$, adenosine, etc.) as well as endothelium derived factors (e.g. $\mathrm{NO}, \mathrm{PGI}_{2}$ ) are important for promoting vasodilation and matching $\mathrm{O}_{2}$ supply with $\mathrm{O}_{2}$ demand during exercise (Dinenno and Joyner 2004).

The SMC resting membrane potential plays a prominent role in setting vascular tone as well as determining vasomotor sensitivity to depolarizing stimuli (i.e. SNA). Modulation of membrane potential may therefore represent an important mechanism by which sympathetic vasoconstriction is attenuated in active skeletal muscle (Thomas et al. 1997). It is well recognized that the inward rectifier $\mathrm{K}^{+}$channels (Kir) exert this control and are capable of hyperpolarizing the SMC membrane resulting in an inhibitory effect on excitability and thus relaxation (Nelson and Quayle 1995). Specifically, the ATP-sensitive $\mathrm{K}^{+}\left(\mathrm{K}_{\mathrm{ATP}}\right)$ channel is activated, in part, by reductions in the ratio of subsarcolemmal ATPto-ADP and may therefore contribute to the integration of cellular metabolism with vasomotor tone across the greater than 2 orders of magnitude increase in muscle metabolism seen with exercise. Importantly, $\mathrm{K}_{\mathrm{ATP}}$ channel activation has been shown to result in SMC hyperpolarization, relaxation of vascular smooth muscle and attenuated $\alpha$ adrenergic vasoconstriction (Quast et al. 1994; Nakai and Ichihara 1994; Tateishi and Faber 1995; Mori et al. 1995). In healthy human forearm muscle the activation of $\mathrm{K}_{\mathrm{ATP}}$ channels increases vasodilation in response to ischemia indicating the potential for $\mathrm{K}_{\mathrm{ATP}}$ channels to contribute substantially to skeletal muscle $\mathrm{O}_{2}$ delivery during exercise (Biljstra et al. 1996b). Despite early studies demonstrating that blockade of $\mathrm{K}_{\mathrm{ATP}}$ channels significantly 
attenuates reactive and functional hyperaemia in humans and animals (Bank et al. 2000, Biljstra et al. 1996a, Banitt et al. 1996) more recent work has failed to confirm these results (Duncker et al. 2001, Farouque et al. 2003, Shrage et al. 2006). Thus, it remains unclear whether the $\mathrm{K}_{\mathrm{ATP}}$ channel represents an obligatory mechanism supporting exercise-induced skeletal muscle hyperaemia. Additionally, given that $\mathrm{K}_{\mathrm{ATP}}$ channels are sensitive to metabolic status and that there exists considerable heterogeneity of metabolic characteristics among and within skeletal muscles it is plausible that $\mathrm{K}_{\mathrm{ATP}}$ channelmediated vasodilation is dependent upon skeletal muscle fibre type distribution; a concept that cannot be addressed in humans with current technology.

The purpose of the present investigation was to test the hypothesis that blockade of $\mathrm{K}_{\mathrm{ATP}}$ channels via glibenclamide (GLI) would reduce hindlimb skeletal muscle blood flow (BF) and vascular conductance (VC) and increase arterial blood [lactate] during submaximal treadmill exercise in healthy rats. Furthermore, given the purported coupling of cellular metabolism with vasomotor tone by $\mathrm{K}_{\mathrm{ATP}}$ channels, it was anticipated that the reductions in VC with GLI would associate directly with the percentage of type I and type IIa fibres across muscles. 
Methods

\section{Ethical approval}

All procedures were approved by the Institutional Animal Care and Use Committee of Kansas State University under the guidelines established by the National Institutes of Health and conducted according to the animal use guidelines mandated by The Journal of Physiology (Drummond, 2009). 14 adult male Sprague-Dawley rats ( 4 months old, body mass $=366 \pm 7 \mathrm{~g}$ ) were maintained in accredited animal facilities (Association for the Assessment and Accreditation of Laboratory Animal Care) at Kansas State University on a 12-h light/12-h dark cycle with food and water provided ad libitum. Rats were separated into either rest $(n=6)$ or exercise $(n=8)$ groups and used for within-animal comparisons under control (CON) and $\mathrm{K}_{\mathrm{ATP}}$ channel blockade (GLI) conditions. Rats were acclimatized to running during a familiarization period comprised of 5-7 sessions on a custom-built motor-driven treadmill set at an incline of 5\%. Each session consisted of running at $20 \mathrm{~m}$ $\min ^{-1}$ over a total duration of no more than $5 \mathrm{~min}$.

The pharmacological sulphonylurea derivative GLI (494 $\mathrm{g} \mathrm{mol}^{-1}$; 5-chloro- $N$-(4-[N(cyclohexylcarbamoyl)sulfamoyl]phenethyl)-2-methoxybenzamide; Sigma-Aldrich, St Louis, MO, USA) was used to achieve blockade of vascular $\mathrm{K}_{\mathrm{ATP}}$ channels. Briefly, $50 \mathrm{mg}$ of GLI was dissolved in $4 \mathrm{ml}$ of $\mathrm{NaOH}(0.1 \mathrm{M})$ to produce a $12.5 \mathrm{mg} \mathrm{ml}^{-1}$ stock solution. A $5 \mathrm{mg} \mathrm{kg}^{-1}$ dose was drawn from the stock solution and diluted to $\sim 1 \mathrm{ml}$ with heparinized saline. It has been reported previously that GLI is a selective $\mathrm{K}_{\mathrm{ATP}}$ channel blocker at concentrations below $5 \mu \mathrm{mol} \mathrm{L}{ }^{-1}$ (Beech et al. 1993, Sadraei and Beech 1995a). The current dose of $5 \mathrm{mg} \mathrm{kg}^{-1}$ for rats of a mean body mass of 366 g equates to a blood concentration of $\sim 140 \mu \mathrm{mol} \mathrm{L}{ }^{-1}$. Given that 98-99\% of GLI is bound to plasma protein, the effective blood concentration of GLI is $\sim 2-3 \mu \mathrm{mol} \mathrm{L}^{-1}$ (George et al. 1990) which is in the range for GLI to be selective for $\mathrm{K}_{\mathrm{ATP}}$ channels. 


\section{Surgical instrumentation}

On the day of the final protocol the rats were anesthetized initially with a 5\% isoflurane- $\mathrm{O}_{2}$ mixture and maintained on a $3 \%$ isoflurane- $\mathrm{O}_{2}$ mixture for the duration of the surgical instrumentation. Cannulation of both the carotid and caudal arteries was performed with PE-10 connected to PE-50 (Intra-Medic polyethylene tubing, BD, Franklin Lakes, NJ, USA). The catheters were then tunneled subcutaneously to the dorsal aspect of the cervical region where they were exteriorized through a puncture wound in the skin. Following closure of incisions the rat was removed from anesthesia and given a minimum recovery period of $2 \mathrm{~h}$.

\section{Experimental protocol}

After the recovery period the exercise BF protocol $(n=8)$ was performed with the treadmill set at an incline of 5\%. The rat was placed on the treadmill and the carotid catheter was attached to a pressure transducer (P23ID, Gould Statham Instruments, Hato Rey, Puerto Rico, USA) for the measurement of mean arterial pressure (MAP) and HR while the caudal catheter was connected to a 1-ml syringe attached to a Harvard pump (model 907, Holliston, MA, USA). Exercise was initiated at a speed of $\sim 20 \mathrm{~m} \mathrm{~min}^{-1}$ and remained steady for $\sim 3$ min at which time pre-microspheres HR and pressures were recorded. At $\sim 3.5$ min of total exercise time blood withdrawal was initiated from the caudal catheter at a rate of $0.25 \mathrm{ml} \mathrm{min}^{-1}$. The carotid catheter was then disconnected from the pressure transducer and $\sim 0.5-0.610^{6}, 15 \mu$ m diameter microspheres $\left({ }^{57} \mathrm{Co}\right.$ or ${ }^{85} \mathrm{Sr}$ in random order, Perkin Elmer Life and Analytical Sciences, Waltham, MA, USA) were rapidly infused into the aortic arch of the running animal for the determination of tissue BF. Upon reconnection of the carotid catheter to the pressure transducer a second pressure reading was immediately recorded post-microspheres. An arterial blood sample $(0.2 \mathrm{ml})$ was then drawn from the carotid artery catheter for the determination of blood gases, hematocrit, $\mathrm{pH}$, [lactate] and [glucose]. Exercise was terminated and the rat was continuously monitored during a minimum 30 min rest period before the second bout began. 
A post-recovery pressure was recorded to establish resting pressure and HR values. The $\mathrm{K}_{\text {ATP }}$ channel inhibitor GLI (5 mg kg-1) was infused via the caudal artery catheter. Pressure was monitored continuously until GLI elicited a persistent rise in MAP at which time the second exercise bout was initiated. The second bout and administration of microspheres were performed identically to the protocol described above. Upon exercise termination the rat was euthanized with an overdose of pentobarbital ( $>50 \mathrm{mg} \mathrm{kg}^{-1}$ body mass) via the carotid artery catheter. For a second group of rats $(n=6)$ administration of microspheres, blood sampling and pressure recordings were performed at rest under CON and GLI conditions as described above.

\section{Determination of $B F$ and $V C$}

Correct placement of the carotid catheter in the aortic arch was verified by anatomical dissection. Hindlimb muscles and muscle portions as well as the lungs, kidneys, and representative organs of the splanchnic region were removed, weighed and placed in counting vials for the determination of radioactivity.

Radioactivity was measured for each tissue as well as the reference sample using a gamma scintillation counter (model 5230, Packard Auto Gamma Spectrometer, Downers Grove, IL, USA). Taking into account the cross-talk fraction between isotopes enabled radioactivity to be determined for separate microsphere injections $\left({ }^{57} \mathrm{Co}\right.$ or $\left.{ }^{85} \mathrm{Sr}\right)$. Based on this radioactivity BF to each tissue was determined for the individual conditions, CON or GLI, by comparison to the reference sample of known flow rate and measured radioactivity (Ishise et al. 1980, Musch and Terrell 1992). Tissue BFs were expressed as $\mathrm{ml} \mathrm{min}^{-1}$ (100 $\mathrm{g})^{-1}$ of tissue and the results were also normalized to MAP and expressed as VC (ml min ${ }^{-1}$ $\left(100 \mathrm{~g}^{-1} \mathrm{mmHg}^{-1}\right)$. Adequate mixing of the microspheres for each BF determination was verified by a $<15 \%$ difference in BF between the right and left kidneys or right and left hindlimbs. 


\section{Statistical analysis}

$\mathrm{BF}$ and VC were compared between and within groups using mixed two-way ANOVA's and Student-Newman-Keuls post hoc tests where appropriate. Muscle fibre-type composition was based on the percentage of type I, type IIa, type IIb, and type IId/x fibres in the individual muscles and muscle parts of the rat hindlimb as reported by Delp and Duan (1996). Pearson Product Correlations were used to test the relationship between changes in VC and muscle fibre type. Significance was set at $P<0.05$ and values are expressed as mean \pm SEM. 
Results

There was no significant difference in body mass between groups (Rest: $365 \pm 5$, Exercise: $367 \pm 13 \mathrm{~g}, P>0.05)$.

Effects of GLI on HR, MAP, blood gases, pH, hematocrit, [lactate] and [glucose]

At rest and during exercise MAP was higher and HR was lower with GLI compared to CON (Fig. 1). During exercise hematocrit was higher with GLI (CON: $31 \pm 1$, GLI: $33 \pm$ $1 \%, P<0.05$ ), but $\mathrm{pH}, \mathrm{PO}_{2}, \mathrm{PCO}_{2}$ and $\mathrm{O}_{2}$ saturation were not different between conditions (data not shown, $P>0.05$ for all). Blood [lactate] was higher with GLI during exercise but not at rest (Fig. 4). Blood [glucose] was not significantly different with GLI during exercise (CON: $\left.99.1 \pm 4.0, \mathrm{GLI}: 98.7 \pm 5.8 \mathrm{mg} \mathrm{dL}^{-1}, P>0.05\right)$.

Effects of GLI on skeletal muscle BF and VC

At rest there were no differences between groups in total hindlimb skeletal muscle BF or VC (Fig. 2, $P=0.23$ ) or BF and VC to 26 of 28 individual muscles or muscle portions (exception: VC was lower with GLI in the red gastrocnemius and vastus intermedius (Tables 2 and 3)). During exercise both total hindlimb skeletal muscle BF and VC were lower with GLI compared to CON (Fig. 2). Specifically, GLI resulted in a lower $\mathrm{BF}$ in 12, and lower VC in 16, of the 28 individual hindlimb muscles or muscle portions during exercise (Tables 2 and 3). Furthermore, there was a significant negative correlation between the percentage of type I and type IIa fibres and the percent change in VC for the 28 muscles or muscle portions of the hindlimb (Fig. 3; $r=-0.53, P<0.05$ ).

Effects of GLI on renal and splanchnic BF and VC at rest and during exercise

Renal BF and VC were reduced by GLI at rest but not during exercise (Table 3). Among the representative organs of the splanchnic region BF was reduced at rest to the stomach, adrenals and large intestine with GLI. VC was reduced at rest to the stomach, adrenals, spleen, small intestine and large intestine with GLI. BF during exercise with GLI 
was reduced to the pancreas and small intestine, and VC was reduced to the stomach, pancreas and small intestine (Table 3). 


\section{Discussion}

The primary original findings of this investigation were that the blockade of $\mathrm{K}_{\mathrm{ATP}}$ channels in the rat via GLI increased MAP and decreased HR at rest and during treadmill exercise, reduced exercising hindlimb skeletal muscle BF and VC and increased exercising blood [lactate]. Furthermore, the decreases in VC with GLI reflected a fibre type-selective effect such that VC was reduced primarily to the muscles comprised of type I and type IIa fibres. These data suggest that $\mathrm{K}_{\mathrm{ATP}}$ channels contribute significantly to exercise-induced skeletal muscle hyperaemia during treadmill exercise.

The finding that GLI increased MAP with a consequent decrease in HR is not surprising as this is consistent with previous reports in rats (Moreau et al. 1994, Gardiner et al. 1996), swine (Duncker et al. 2001) and humans (Farouque et al. 2003). Specifically, the higher MAP and lower HR at rest with $\mathrm{K}_{\mathrm{ATP}}$ channel blockade were coincident with large reductions in renal and splanchnic VC. This is in agreement with studies demonstrating a significant contribution of $\mathrm{K}_{\mathrm{ATP}}$ channels to basal vasomotor tone in the systemic circulation of conscious rats (Gardiner et al. 1996, Moreau et al. 1994, Parekh and Zou 1996), hamsters (Jackson et al. 1993, Saito et al. 1996) and dogs (Vanelli and Hussain 1994, Comtois et al. 1994).

The similar hindlimb skeletal muscle BF and VC at rest with GLI is most likely due to the inhibition of $\mathrm{K}_{\mathrm{ATP}}$ channels at physiological ATP concentrations or a compensatory vasodilation by redundant pathways (e.g. $\mathrm{NO}, \mathrm{PGI}_{2}$, baroreflex) to maintain appropriate basal vasomotor tone (Hellsten et al. 2012). Similar observations have been made across species (Duncker et al. 2001, Farouque et al. 2003) although there is some evidence for modest skeletal muscle vascular $\mathrm{K}_{\mathrm{ATP}}$ channel activity at rest (Neilsen et al. 2003). In the present study, for example, the vastus intermedius was one of few hindlimb muscles to evince a GLI-induced reduction in BF and VC at rest. Given that the rat vastus intermedius is a postural muscle it is plausible that it would possess a relatively low subsarcolemmal ATP-to-ADP ratio resulting in a greater $\mathrm{K}_{\mathrm{ATP}}$ channel open probability at resting metabolic 
rates compared to the vast majority of the hindlimb muscle vasculature evidencing little or no basal $\mathrm{K}_{\mathrm{ATP}}$ channel activation.

Previously, $\mathrm{K}_{\mathrm{ATP}}$ channel blockade in rats and hamsters has been shown to reduce the skeletal muscle hyperaemic response to electrically-induced contractions (Thomas et al. 1997, Saito et al. 1996). In this regard, our findings indicate that, in rats, $\mathrm{K}_{\mathrm{ATP}}$ channel blockade also reduces the in vivo skeletal muscle hyperaemic response to treadmill running. This corroborates the notion that $\mathrm{K}_{\mathrm{ATP}}$ channels represent an important mechanistic link between metabolism and vasomotor tone during exercise. The 20\% decrease in exercising hindlimb skeletal muscle VC with GLI suggests that the rat locomotor muscle vascular bed contains a substantial pool of $\mathrm{K}_{\text {ATP }}$ channels which are activated even at moderate exercise intensities. Importantly, the $16 \%$ decrease in exercising hindlimb skeletal muscle BF occurred simultaneous with a doubling of arterial blood [lactate] (2.0 to $4.1 \mathrm{mmol} \mathrm{L}^{-1}$ ) with GLI. Thus, not only is vasodilation attenuated in the hindlimb vasculature, but this decrement represents an impaired vasomotor control failing to meet the BF demands of the active skeletal muscle. These intriguing findings support the hypothesis that $\mathrm{K}_{\mathrm{ATP}}$ channels are obligatory for exercise-induced hyperaemia with respect to exercise tolerance and work capacity; at least within the rat.

The doubling of arterial blood [lactate] is not surprising given that GLI-induced decreases in BF were correlated with the percent type I and IIa fibres such that the predominantly oxidative muscles and muscle portions experienced the most consistent decrease in BF during exercise. However, muscle fibre type composition only explains a modest portion ( 28\%) of the VC decrease with GLI. The preferential recruitment of type I and type IIa fibres during the low speed exercise protocol ( $\left.55-65 \% \mathrm{VO}_{2 \max }\right)$ likely explains a significant portion of the fibre type-selective effect. In addition, NO, which has a proportionally greater role in the control of oxidative fibre type vascular beds (Hirai et al. 1994), has been shown to operate through the activation of $\mathrm{K}_{\mathrm{ATP}}$ channels (Tare et al. 1990, Murphy and Braden 1995). Thus, blockade of $\mathrm{K}_{\mathrm{ATP}}$ channels in the vasculature supplying type I and IIa fibres would result in a greater decrement to VC during exercise as it may block a portion of this NO-mediated vasodilation. 
With respect to the interpretation of the effects of GLI on altered BF and VC as purely local muscle effects, the possible impacts of $\mathrm{K}_{\mathrm{ATP}}$ channel blockade on sympathetic nerve discharge must be considered. The loss of $\mathrm{K}_{\mathrm{ATP}}$ channel-mediated hyperpolarization could conceivably result in increased sympathetic nerve discharge for a given stimulus which would account, in part, for the decrements in BF and VC seen herein. However, we consider this unlikely because it has been demonstrated, in male Sprague Dawley rats, that direct injection of GLI into the rostral ventrolateral medulla has no effect on blood pressure, HR or renal SNA (Guo et al. 2011). Furthermore, preliminary studies from our lab demonstrate that arterial infusion of GLI in the rat actually reduced renal and lumbar SNA consistent with an appropriate baroreflex response to the reduction in VC elicited by GLI (CT Holdsworth, TI Musch, DC Poole, unpublished observations). Taken together, these findings indicate that GLI did not directly impact sympathetic nerve discharge in the current study and that the reductions in BF and VC are the result, specifically, of muscle vascular $\mathrm{K}_{\mathrm{ATP}}$ channel blockade.

It is important to note that the BF and VC results seen herein run contrary to data from exercising swine (Duncker et al. 2001). This may be the result of cross-species differences in vascular $\mathrm{K}_{\mathrm{ATP}}$ channel expression and/or function. Indeed, while the octameric structure of vascular $\mathrm{K}_{\mathrm{ATP}}$ channels is presumed to be the Kir6.1 pore-forming units with associated SUR2B subunits, considerable heterogeneity of functional expression has been demonstrated through readily occurring heteromultimerization of the pore forming units (Kir6.x) as well as the sulphonylurea receptor subunits (SURx) which confer the channel's ATP sensitivity. Accordingly, there is substantial variation in unitary conductance which may impact the relative importance of the $\mathrm{K}_{\mathrm{ATP}}$ channel in vasomotor control across species, tissue beds, and metabolic rates (Teramoto et al. 2006). This is particularly true for vascular $\mathrm{K}_{\mathrm{ATP}}$ channels as the range of unitary conductance appears to be much greater ( $\sim 20$ to $>200 \mathrm{pS})$ than for pancreatic $\beta$ cells ( $\sim 0$ to $90 \mathrm{pS}$ ) and some regions of the heart and brain ( 40 to 80 pS) (Cole and Clément-Chomienne 2003). Further exploration of the discrepancies in channel molecular structure across tissues may lead to 
better understanding of the functional consequences resulting from global $\mathrm{K}_{\mathrm{ATP}}$ channel blockade.

The role of $\mathrm{K}_{\mathrm{ATP}}$ channels in the control of human skeletal muscle BF has been elucidated primarily by the use of $\mathrm{K}_{\mathrm{ATP}}$ channel agonists, namely nicorandil and diazoxide, as well as the $\mathrm{K}_{\mathrm{ATP}}$ channel inhibitor GLI. Seminal results include $\mathrm{K}_{\mathrm{ATP}}$ channel agonists eliciting forearm vasodilation (Biljstra et al. 1996b) and $\mathrm{K}_{\mathrm{ATP}}$ channel blockade reducing the BF response to both reactive and functional hyperaemia in some (Bank et al. 2000, Biljstra et al. 1996a, Banitt et al. 1996) but not all studies (Farouque et al. 2003, Schrage et al. 2006). The reason for the differential conclusions drawn from use of $K_{\text {ATP }}$ channel agonists versus blockers is unclear. In healthy humans, $\mathrm{K}_{\mathrm{ATP}}$ channels may not be obligatory for achieving adequate skeletal muscle BF during exercise given the great redundancy of vasodilatory mediators (Hellsten et al. 2012). The potential for parallel pathways such as NO- and $\mathrm{PGI}_{2}$-mediated vasodilation to adequately meet BF requirements is present at relatively low workloads. This notion is consistent with $\mathrm{K}_{\mathrm{ATP}}$ blockade studies in humans involving the forearm musculature which represents a small, non-locomotory portion of the total body muscle mass. Furthermore, the putative variability of $\mathrm{K}_{\mathrm{ATP}}$ channel expression among skeletal muscle vascular beds with vastly different metabolic characteristics may confound interpretation of the available human data. It appears that the vascular $\mathrm{K}_{\mathrm{ATP}}$ channel subtype uniquely requires nucleotide diphosphates (i.e. ADP) for activation and thus is designated as a nucleotide-dependent $\mathrm{K}^{+}$channel $\left(\mathrm{K}_{\mathrm{NDP}}\right)$ (Beech et al. 1993). As such, the channel would only demonstrate obligatory function where sufficiently low blood-smooth muscle cell $\mathrm{O}_{2}$ driving pressures result in pronounced subsarcolemmal ADP accumulation. Under these conditions even a small impact of $\mathrm{K}_{\mathrm{ATP}}$ channel activation on SMC membrane potential could drive large increases in vasodilation. This is due to the remarkably steep relationship between membrane potential and $\mathrm{Ca}^{2+}$ influx in smooth muscle; changes of only a couple millivolts can reduce $\left[\mathrm{Ca}^{2+}\right]_{\mathrm{i}} \sim 30 \%$ (Nelson et al. 1990). For this reason we are in agreement with Shrage and colleagues (2006) who have recognized that the determination of $\mathrm{K}_{\mathrm{ATP}}$ channel function across more diverse muscle 
vascular beds and a greater range of exercise intensities/paradigms are necessary to resolve the circumstances under which these channels may impact $\mathrm{O}_{2}$ delivery.

The results seen herein appear to suggest that the role of $\mathrm{K}_{\mathrm{ATP}}$ channels may be potentiated under conditions of low $\mathrm{O}_{2}$ tension (i.e. when muscle fibres are recruited) which can increase glycolytic flux and drive greater intracellular ADP accumulation. This environment is exacerbated in muscle fibres with low oxidative potential when exposed to high metabolic demand as well as conditions characterized by skeletal muscle hypoxia such as heart failure (Poole et al. 2012) type II diabetes (Padilla et al. 2007) and ageing (Poole and Ferreira 2007). Therefore, the potential for $\mathrm{K}_{\mathrm{ATP}}$ channels to contribute significantly to exercise-induced skeletal muscle hyperaemia has important implications for characterizing the etiology of blood-muscle $\mathrm{O}_{2}$ transport decrements in these conditions. For example, in diabetics, increased blood glucose levels cause overexposure to the carboxyl radical methylglycoxal which has been shown to decrease membrane expression of vascular $\mathrm{K}_{\mathrm{ATP}}$ channels (Yang et al. 2012). Accordingly, $\mathrm{K}_{\text {ATP }}$ channel-mediated vasodilation may be attenuated in diabetes and would contribute to the reduction in skeletal muscle microvascular $\mathrm{O}_{2}$ driving pressures described for this condition (Padilla et al. 2007). Additionally, this would explain why GLI administration for the management of insulin release in diabetics does not impact exercise tolerance as the $\mathrm{K}_{\mathrm{ATP}}$ channel-mediated vasodilation may already demonstrate reduced function prior to blockade (Cunha et al. 2008). The development of novel therapeutics targeting $K_{\text {ATP }}$ channel membrane expression and activation may provide an exciting and powerful tool for improving $\mathrm{O}_{2}$ transport and subsequent exercise performance in populations exhibiting vascular dysfunction (Poole et al. 2012).

\section{Experimental considerations}

Since GLI is not selective for skeletal muscle $\mathrm{K}_{\mathrm{ATP}}$ channels it might be argued that GLI-induced $\mathrm{K}_{\mathrm{ATP}}$ channel blockade in the coronary vasculature (or some other vascular compartment) could account for the reduced BF during exercise seen herein. Measurements of coronary BF and VC were not available in the present investigation. However, 
decrements in cardiac output would not be expected to support a selective decrease in BF for 12 of the 28 muscles or muscle portions as seen herein. This observation suggests that GLI would not impact coronary BF to the extent that decrements in cardiac function could impact hindlimb skeletal muscle BF during submaximal treadmill exercise.

\section{Conclusions}

Our principal novel findings show that blockade of $\mathrm{K}_{\text {ATP }}$ channels via GLI (5 mg $\mathrm{kg}^{-1}$ ) attenuates hindlimb skeletal muscle BF and VC and elevates blood [lactate] during submaximal treadmill exercise. These results provide evidence that $\mathrm{K}_{\mathrm{ATP}}$ channel-induced hyperpolarization constitutes an important mechanism of vasomotor control in exercising skeletal muscle and suggest that $\mathrm{K}_{\text {ATP }}$ channels represent an obligatory pathway for skeletal muscle vascular control during large muscle mass exercise in healthy rats. 
References

Bank AJ, Sih R, Mullen K, Osayamwen M, Lee PC (2000). Vascular ATPdependent potassium channels, nitric oxide, and human forearm reactive hyperaemia. Cardiovasc Drugs Ther 14, 23-29.

Banitt PF, Smits P, Williams SB, Ganz P, Creager MA (1996). Activation of ATPsensitive potassium channels contributes to reactive hyperaemia in humans. Am J Physiol 271, H1594-H1598.

Beech DJ, Zhang H, Nakao K, Bolton TB (1993). Single channel and whole-cell K-currents evoked by levcromakalim in smooth muscle cells from the rabbit portal vein. $\mathrm{Br} J$ Pharmacol 110, 583-590.

Beech DJ, Zhang H, Nakao K, Bolton TB (1993). K channel activation by nucleotidediphosphates and its inhibition by glibenclamide in vascular smooth muscle cells. Br J Pharmacol 110, 573-582.

Bijlstra PJ, den Arend JA, Lutterman JA, Russel FG, Thien T, Smits P (1996). Blockade of vascular ATP-sensitive potassium channels reduces the vasodilator response to ischaemia in humans. Diabetologia 39, 1562-1568.

Bijlstra PJ, Lutterman JA, Russel FG, Thien T, Smits P (1996). Interaction of sulphonylurea derivatives with vascular ATP-sensitive potassium channels in humans. Diabetologia 39, 1083-1090.

Cole WC \& Clément-Chomienne O (2003). ATP-sensitive K+ channels of vascular smooth muscle cells. J Cardiovasc Electrophysiol 14, 94-103.

Comtois A, Sinderby C, Comtois N, Grassino A, Renaud JM (1994). An ATP-sensitive potassium channel blocker decreases diaphragmatic circulation in anesthetized dogs. $J$ Appl Physiol 77, 127-134. 
Cunha MR, Silva ME, Machado HA, Fukui RT, Correia MR, Santos RF, Wajchenberg BL, Rocha DM, Rondon MU, Negrão CE, Ursich MJ (2008). Cardiovascular, metabolic and hormonal responses to the progressive exercise performed to exhaustion in patients with type 2 diabetes treated with metformin or glyburide. Diabetes Obes Metab 10, 238-245.

Delp MD \& Duan C (1996). Composition and size of type I, IIA, IID/X, and IIB fibers and citrate synthase activity of rat muscle. J Appl Physiol 80, 261-70.

Dinenno FA \& Joyner MJ (2004). Combined NO and PG inhibition augments $\alpha$-adrenergic vasoconstriction in contracting human skeletal muscle. Am J Physiol Heart Circ Physiol 287, H2576-H2584.

Drummond GB (2009). Reporting ethical matters in The Journal of Physiology: standards and advice. $J$ Physiol 587, 713-719.

Duncker DJ, Oei HH, Hu F, Stubenitsky R, Verdouw PD (2001). Role of K+ATP channels in regulation of systemic, pulmonary, and coronary vasomotor tone in exercising swine. Am J Physiol Heart Circ Physiol 280, H22-H33.

Farouque HM \& Meredith IT (2003). Effects of inhibition of ATP-sensitive potassium channels on metabolic vasodilation in the human forearm. Clin Sci 104, 39-46.

Gardiner SM, Kemp PA, March JE, Fallgren B, Bennet T (1996). Effects of glibenclamide on the regional haemodynamic actions of $\alpha$-trinositol and its influence on responses to vasodilators in conscious rats. Br J Pharmacol 117, 507-515.

George S, McBurney A, Cole A (1990). Possible protein binding displacement interaction between glibenclamide and metolazone. Eur J Clin Pharmacol 38, 93-95.

Guo Q, Jin S, Wang XL, Wang R, Xiao L, He RR, Wu YM (2011). Hydrogen sulfide in the rostral ventrolateral medulla inhibits sympathetic vasomotor tone through ATPsensitive K+ channels. J Pharmacol Exp Ther 338, 458-465. 
Hammer LW, Ligon AL, Hester RL (2001). Differential inhibition of functional dilation of small arterioles by indomethacin and glibenclamide. Hypertension 37, 599-603.

Hellsten Y, Nyberg M, Jensen LG, Mortensen SP (2012). Vasodilator interactions in skeletal muscle blood flow regulation. J Physiol 590, 6297-6305.

Hirai T, Visneski MD, Kearns KJ, Zelis R, Musch TI (1994). Effects of NO synthase inhibition on the muscular blood flow response to treadmill exercise in rats. J Appl Physiol 77, 1288-1293.

Ishise S, Pegram BL, Yamamoto J, Kitamura Y, Frohlich ED (1980). Reference sample microsphere method: cardiac output and blood flows in conscious rat. Am J Physiol 239, H443-H449.

Jackson WF (1993). Arteriolar tone is determined by activity of ATP-sensitive potassium channels. Am J Physiol 265, H1797-H1803.

Mori HM, Chujo M, Tanaka E, Yamakawa A, Shinozaki Y, Mohamed MU, Nakazawa H (1995). Modulation of adrenergic coronary vasoconstriction via ATP-sensitive potassium channel. Am J Physiol 268, H1077-H1085.

Moreau R, Komeichi H, Kirstetter P, Yang S, Aupetit-Faisant B, Cailmail S, Lebrec D (1994). Effects of glibenclamide on systemic and splanchnic haemodynamics in conscious rats. Br J Pharmacol 112, 649-653.

Murphy ME \& Brayden JE (1995). Nitric oxide hyperpolarizes rabbit mesenteric arteries via ATP-sensitive potassium channels. J Physiol 486, 47-58.

Musch TI \& Terrell JA (1992). Skeletal muscle blood flow abnormalities in rats with a chronic myocardial infarction: rest and exercise. Am J Physiol 262, H411-H419.

Nakai T \& Ichihara K (1994). Effects of diazoxide on norepinephrine-induced vasocontraction and ischemic myocardium in rats. Biol Pharmacol Bull 17, 1341-1344. 
Nelson MT, Patlak JB, Worley JF, Standen NB (1990). Calcium channels, potassium channels, and voltage dependence of arterial smooth muscle tone. Am J Physiol 259, C3-18.

Nelson MT \& Quayle JM (1995). Physiological roles and properties of potassium channels in arterial smooth muscle. Am J Physiol 268, C799-C822.

Nielsen JJ, Kristensen M, Hellsten Y, Bangsbo J, Juel C (2003). Localization and function of ATP-sensitive potassium channels in human skeletal muscle. Am J Physiol Regul Integr Comp Physiol 284, R558-R563.

Padilla DJ, McDonough P, Behnke BJ, Kano Y, Hageman KS, Musch TI, Poole DC (2007). Effects of Type II diabetes on muscle microvascular oxygen pressures. Respir Physiol Neurobiol 156, 187-195.

Parekh N \& Zou AP (1996). Role of prostaglandins in renal medullary circulation: response to different vasoconstrictors. Am J Physiol 271, F653-F658.

Poole DC \& Ferreira LF (2007). Oxygen exchange in muscle of young and old rats: muscle-vascular-pulmonary coupling. Exp Physiol 92, 341-346.

Poole DC, Hirai DM, Copp SW, Musch TI (2012). Muscle oxygen transport and utilization in heart failure: implications for exercise (in)tolerance. Am J Physiol Heart Circul Physiol 302, H1050-H1063.

Quast U, Guillon JM, Cavero I (1994). Cellular pharmacology of potassium channel openers in vascular smooth muscle. Cardiovasc Res 28, 805-810.

Saito Y, McKay M, Eraslan A, Hester RL (1996). Functional hyperaemia in striated muscle is reduced following blockade of ATP-sensitive potassium channels. Am J Physiol Heart Circ Physiol 270, H1649-H1654.

Sadraei H \& Beech DJ (1995). Ionic currents and inhibitory effects of glibenclamide in seminal vesicle smooth muscle cells. Br J Pharmacol 115, 1447-1454. 
Schrage WG, Dietz NM, Joyner MJ (2006). Effects of combined inhibition of ATPsensitive potassium channels, nitric oxide, and prostaglandins on hyperaemia during moderate exercise. J Appl Physiol 100, 1506-1512.

Tare M, Parkington HC, Coleman HA, Neild TO, Dusting GJ (1990). Hyperpolarization and relaxation of arterial smooth muscle caused by nitric oxide derived from the endothelium. Nature 346, 69-71.

Tateishi J \& Faber JE (1995). ATP-sensitive $\mathrm{K}^{+}$channels mediate $\alpha_{2 \mathrm{D}}$-adrenergic receptor contraction of arteriolar smooth muscle and reversal of contraction in hypoxia. Circ Res 76, 53-63.

Teramoto N (2006). Physiological roles of ATP-sensitive $\mathrm{K}^{+}$channels in smooth muscle. $J$ Physiol 572, 617-624.

Thomas GD, Hansen J, Victor RG (1997). ATP-sensitive potassium channels mediate contraction-induced attenuation of sympathetic vasoconstriction in rat skeletal muscle. $J$ Clin Invest 99, 2602-2609.

Thomas GD \& Segal SS (2004). Neural control of muscle blood flow during exercise. $J$ Appl Physiol 97, 731-738.

Vanelli G \& Hussain SN (1994). Effects of potassium channel blockers on basal vascular tone and reactive hyperaemia of canine diaphragm. Am J Physiol 266, H43-H51.

Yang Y, Li S, Konduru AS, Zhang S, Trower TC, Shi W, Cui N, Yu L, Wang Y, Zhu D, Jiang C (2012). Prolonged exposure to methylglyoxal causes disruption of vascular KATP channel by mRNA instability. Am J Physiol Cell Physiol 303, C1045C1054. 
Additional information

Competing interests

None.

Author contributions

Conception and design of the experiments: C.T.H., T.I.M. and D.C.P. Data collection and analysis: C.T.H., S.W.C., S.K.F., G.E.S., T.I.M. and D.C.P. Manuscript preparation and revision: S.W.C., C.T.H., S.K.F., G.E.S., T.I.M. and D.C.P.

Funding

These experiments were funded by a Kansas State University SMILE award to TIM and American Heart Association Midwest Affiliate (10GRNT4350011) and NIH (HL-108328) awards to DCP.

\section{Acknowledgements}

We thank K. Sue Hageman for expert technical assistance and D.M. Hirai for scientific advice. 
Table 1. Effects of GLI on total hindlimb skeletal muscle BF for rest and exercise groups $\left(\mathrm{ml} \min ^{-1}(100 \mathrm{~g})^{-1}\right)$

\begin{tabular}{|c|c|c|c|c|}
\hline & \multicolumn{2}{|c|}{ Rest } & \multicolumn{2}{|c|}{ Exercise } \\
\hline & CON & GLI & CON & GLI \\
\hline \multicolumn{5}{|l|}{ Ankle extensors } \\
\hline Soleus (91\%) & $115 \pm 20$ & $91 \pm 28$ & $382 \pm 19$ & $277 \pm 21 *$ \\
\hline Plantaris (20\%) & $18 \pm 4$ & $16 \pm 4$ & $253 \pm 25$ & $209 \pm 21$ \\
\hline Gastrocnemius, red (86\%) & $57 \pm 18$ & $46 \pm 22$ & $419 \pm 40$ & $337 \pm 33$ \\
\hline Gastrocnemius, white (0\%) & $11 \pm 3$ & $16 \pm 5$ & $53 \pm 13$ & $69 \pm 9$ \\
\hline Gastrocnemius, mixed (9\%) & $20 \pm 5$ & $20 \pm 9$ & $161 \pm 9$ & $152 \pm 16$ \\
\hline Tibialis posterior (27\%) & $26 \pm 10$ & $11 \pm 4$ & $192 \pm 23$ & $161 \pm 16$ \\
\hline Flexor digitorum longus (32\%) & $57 \pm 31$ & $65 \pm 48$ & $118 \pm 17$ & $105 \pm 20$ \\
\hline Flexor halicus longus (29\%) & $16 \pm 4$ & $9 \pm 2$ & $107 \pm 14$ & $87 \pm 12$ \\
\hline
\end{tabular}

\section{Ankle flexors}

$\begin{array}{lllll}\text { Tibialis anterior, red (37\%) } & 59 \pm 17 & 33 \pm 12 & 383 \pm 24 & 337 \pm 39 \\ \text { Tibialis anterior, white (20\%) } & 24 \pm 8 & 17 \pm 4 & 136 \pm 12 & 139 \pm 18 \\ \text { Extensor digitorum longus (24\%) } & 22 \pm 5 & 20 \pm 5 & 70 \pm 5 & 72 \pm 5 \\ \text { Peroneals (33\%) } & 27 \pm 7 & 18 \pm 7 & 169 \pm 13 & 144 \pm 19\end{array}$

Knee extensors

Vastus intermedius (96\%)

Vastus medialis (18\%)

Vastus lateralis, red (65\%)

Vastus lateralis, white (0\%)

Vastus lateralis, mixed (11\%)

Rectus femoris, red (34\%)

Rectus femoris, white (0\%)

\section{Knee flexors}

Biceps femoris anterior (0\%)

Biceps femoris posterior (8\%)

Semitendinosus (17\%)

Semimembranosus, red (28\%)

Semimembranosus, white (0\%)

Thigh adductors

Adductor longus (95\%)
Adductor magnus \& brevis (11\%)
Gracilis (23\%)
Pectineus (31\%)

$\begin{array}{llll}134 \pm 34 & 101 \pm 44 & 419 \pm 25 & 299 \pm 18^{*} \\ 38 \pm 14 & 30 \pm 12 & 249 \pm 15 & 186 \pm 11^{*} \\ 88 \pm 37 & 87 \pm 45 & 464 \pm 27 & 306 \pm 42^{*} \\ 10 \pm 2 & 14 \pm 4 & 56 \pm 20 \dagger & 57 \pm 14 \\ 24 \pm 8 & 24 \pm 8 & 200 \pm 12 \dagger & 139 \pm 16^{*} \\ 38 \pm 11 & 28 \pm 13 & 324 \pm 29 & 233 \pm 25^{*} \\ 21 \pm 4 & 16 \pm 5 & 146 \pm 15 & 113 \pm 10^{*}\end{array}$

$\begin{array}{llll}12 \pm 3 & 12 \pm 2 & 34 \pm 4 & 41 \pm 6 \\ 20 \pm 7 & 16 \pm 5 & 106 \pm 11 & 93 \pm 10 \\ 23 \pm 7 & 15 \pm 4 & 77 \pm 7 & 77 \pm 15 \\ 25 \pm 12 & 17 \pm 4 & 137 \pm 19 & 123 \pm 14 \\ 13 \pm 2 & 10 \pm 1 & 40 \pm 6 & 47 \pm 7\end{array}$

$\begin{array}{llll}97 \pm 14 & 74 \pm 20 & 396 \pm 18 & 251 \pm 32^{*} \\ 31 \pm 14 & 22 \pm 7 & 142 \pm 10 & 99 \pm 6^{*} \\ 23 \pm 9 & 14 \pm 3 & 81 \pm 13 & 58 \pm 7 \\ 29 \pm 10 & 20 \pm 6 & 104 \pm 19 & 58 \pm 8^{*}\end{array}$

Data are mean \pm SEM. Values in parentheses indicate \% type I + lla according to Delp \& Duan (1996). Rest; $n=6$, Exercise; $n=8$. ${ }^{*} p<0.05$ versus control. 
Table 2. Effects of GLI on total hindlimb skeletal muscle VC for rest and exercise groups $\left(\mathrm{ml} \mathrm{min}{ }^{-1}\left(100 \mathrm{~g}^{-1} \mathrm{mmHg}^{-1}\right)\right.$

\begin{tabular}{llllllll}
\hline \hline & \multicolumn{3}{c}{ Rest } & & \multicolumn{2}{c}{ Exercise } \\
\cline { 2 - 3 } \cline { 5 - 6 } & & CON & GLI & & CON & GLI \\
\hline Ankle extensors & & & & & & &
\end{tabular}

Soleus (91\%)

Plantaris (20\%)

Gastrocnemius, red (86\%)

Gastrocnemius, white (0\%)

Gastrocnemius, mixed (9\%)

Tibialis posterior $\mathbf{2 7 \% )}$

Flexor digitorum longus (32\%)

Flexor halicus longus (29\%)

\section{Ankle flexors}

Tibialis anterior, red (37\%)

Tibialis anterior, white (20\%)

Extensor digitorum longus (24\%)

Peroneals (33\%)

Knee extensors

Vastus intermedius (96\%)

Vastus medialis (18\%)

Vastus lateralis, red (65\%)

Vastus lateralis, white (0\%)

Vastus lateralis, mixed (11\%)

Rectus femoris, red (34\%)

Rectus femoris, white (0\%)

\section{Knee flexors}

Biceps femoris anterior (0\%)

Biceps femoris posterior (8\%)

Semitendinosus (17\%)

Semimembranosus, red (28\%)

Semimembranosus, white (0\%)

\section{Thigh adductors}

Adductor longus (95\%)

Adductor magnus \& brevis (11\%)

Gracilis (23\%)

Pectineus (31\%)

$\begin{array}{ll}0.88 \pm 0.15 & 0.62 \pm 0.21 \\ 0.14 \pm 0.03 & 0.11 \pm 0.03 \\ 0.44 \pm 0.15 & 0.30 \pm 0.14 \\ 0.09 \pm 0.03 & 0.10 \pm 0.03 \\ 0.16 \pm 0.04 & 0.13 \pm 0.06 \\ 0.21 \pm 0.08 & 0.07 \pm 0.02 \\ 0.41 \pm 0.21 & 0.38 \pm 0.26 \\ 0.12 \pm 0.03 & 0.06 \pm 0.01\end{array}$

$0.45 \pm 0.13$

$0.19 \pm 0.06$

$0.16 \pm 0.04$

$0.22 \pm 0.06$

$0.20 \pm 0.06$

$0.11 \pm 0.03$

$0.13 \pm 0.03$

$0.12 \pm 0.04$

$\begin{array}{ll}1.04 \pm 0.28 & 0.70 \pm 0.30 * \\ 0.30 \pm 0.12 & 0.20 \pm 0.08 \\ 0.71 \pm 0.31 & 0.59 \pm 0.29 \\ 0.08 \pm 0.01 & 0.10 \pm 0.03 \\ 0.19 \pm 0.07 & 0.16 \pm 0.05 \\ 0.29 \pm 0.08 & 0.18 \pm 0.09 \\ 0.17 \pm 0.04 & 0.11 \pm 0.03\end{array}$

$3.00 \pm 0.18$

$1.79 \pm 0.13$

$3.34 \pm 0.24$

$0.40 \pm 0.15$

$1.44 \pm 0.11$

$2.35 \pm 0.26$

$1.05 \pm 0.13$

$2.06 \pm 0.16^{*}$

$1.29 \pm 0.11 *$

$2.12 \pm 0.34 *$

$0.40 \pm 0.10$

$0.96 \pm 0.13^{*}$

$1.62 \pm 0.21 *$

$0.78 \pm 0.08 *$

$\begin{array}{llll}0.10 \pm 0.03 & 0.08 \pm 0.02 & 0.24 \pm 0.03 & 0.28 \pm 0.04 \\ 0.16 \pm 0.05 & 0.10 \pm 0.03 & 0.76 \pm 0.08 & 0.64 \pm 0.07 \\ 0.19 \pm 0.06 & 0.10 \pm 0.02 & 0.55 \pm 0.05 & 0.52 \pm 0.10 \\ 0.20 \pm 0.09 & 0.12 \pm 0.03 & 0.98 \pm 0.14 & 0.84 \pm 0.09 \\ 0.10 \pm 0.02 & 0.07 \pm 0.01 & 0.28 \pm 0.04 & 0.32 \pm 0.04\end{array}$

$\begin{array}{llll}0.76 \pm 0.11 & 0.50 \pm 0.15 & 2.85 \pm 0.16 & 1.74 \pm 0.25^{*} \\ 0.25 \pm 0.11 & 0.15 \pm 0.05 & 1.02 \pm 0.08 & 0.68 \pm 0.05^{*} \\ 0.18 \pm 0.07 & 0.09 \pm 0.02 & 0.58 \pm 0.09 & 0.39 \pm 0.04^{*} \\ 0.23 \pm 0.08 & 0.13 \pm 0.04 & 0.75 \pm 0.14 & 0.40 \pm 0.05^{*}\end{array}$

Data are mean \pm SEM. Values in parentheses indicate \% type I + lla according to Delp \& Duan (1996). Rest; $n=6$, Exercise; $n=8 .{ }^{*} P<0.05$ versus control 
Table 3. Effects of GLI on BF $\left(\mathrm{ml} \mathrm{min}^{-1}(100 \mathrm{~g})^{-1}\right)$ and VC $\left(\mathrm{ml} \mathrm{min}^{-1}(100 \mathrm{~g})^{-1} \mathrm{mmHg}^{-1}\right)$ of the kidneys and organs of the splanchnic region for rest and exercise groups.

\begin{tabular}{lccccc}
\hline \hline & \multicolumn{2}{c}{ Rest } & & \multicolumn{2}{c}{ Exercise } \\
\cline { 2 - 3 } \cline { 5 - 6 } & CON & GLI & & CON & GLI \\
\hline BF & & & & \\
Kidney & $488 \pm 50$ & $380 \pm 27^{*}$ & & $455 \pm 42$ & $417 \pm 47$ \\
Stomach & $100 \pm 21$ & $48 \pm 8^{*}$ & & $101 \pm 15$ & $73 \pm 27$ \\
Adrenals & $718 \pm 144$ & $405 \pm 45$ & & $448 \pm 55$ & $419 \pm 69$ \\
Spleen & $397 \pm 82$ & $307 \pm 88$ & & $113 \pm 28$ & $115 \pm 31$ \\
Pancreas & $142 \pm 26$ & $108 \pm 15$ & & $198 \pm 31$ & $92 \pm 22^{*}$ \\
Sm. Intestine & $304 \pm 41$ & $257 \pm 37$ & & $304 \pm 40$ & $229 \pm 40^{*}$ \\
Lg. Intestine & $218 \pm 48$ & $98 \pm 14^{*}$ & & $153 \pm 30$ & $116 \pm 28^{*}$ \\
Liver** & $31 \pm 6$ & $37 \pm 9$ & & $20 \pm 7$ & $20 \pm 6$ \\
& & & & \\
VC & & & & \\
Kidney & $3.82 \pm 0.50$ & $2.53 \pm 0.24^{*}$ & & $3.30 \pm 0.36$ & $2.88 \pm 0.36$ \\
Stomach & $0.76 \pm 0.15$ & $0.32 \pm 0.04^{*}$ & & $0.64 \pm 0.08$ & $0.33 \pm 0.05^{*}$ \\
Adrenals & $5.73 \pm 1.32$ & $2.69 \pm 0.33$ & & $3.17 \pm 0.35$ & $2.92 \pm 0.55$ \\
Spleen & $3.08 \pm 0.66$ & $1.99 \pm 0.54^{*}$ & & $0.83 \pm 0.23$ & $0.82 \pm 0.24$ \\
Pancreas & $1.13 \pm 0.22$ & $0.72 \pm 0.12$ & $1.46 \pm 0.26$ & $0.65 \pm 0.16^{*}$ \\
Sm. Intestine & $2.35 \pm 0.31$ & $1.71 \pm 0.27$ & $2.23 \pm 0.35$ & $1.62 \pm 0.31^{*}$ \\
Lg. Intestine & $1.72 \pm 0.38$ & $0.64 \pm 0.07^{*}$ & $1.11 \pm 0.25$ & $0.90 \pm 0.21$ \\
Liver** & $0.24 \pm 0.05$ & $0.24 \pm 0.06$ & $0.14 \pm 0.04$ & $0.14 \pm 0.04$ \\
& & & &
\end{tabular}

Data are mean \pm SEM. Rest; $n=6$, Exercise; $n=8 .^{*} P<0.05$ versus control. ${ }^{* *}$ Indicates arterial, not portal, $\mathrm{BF}$ and VC 
Figure 1

A.

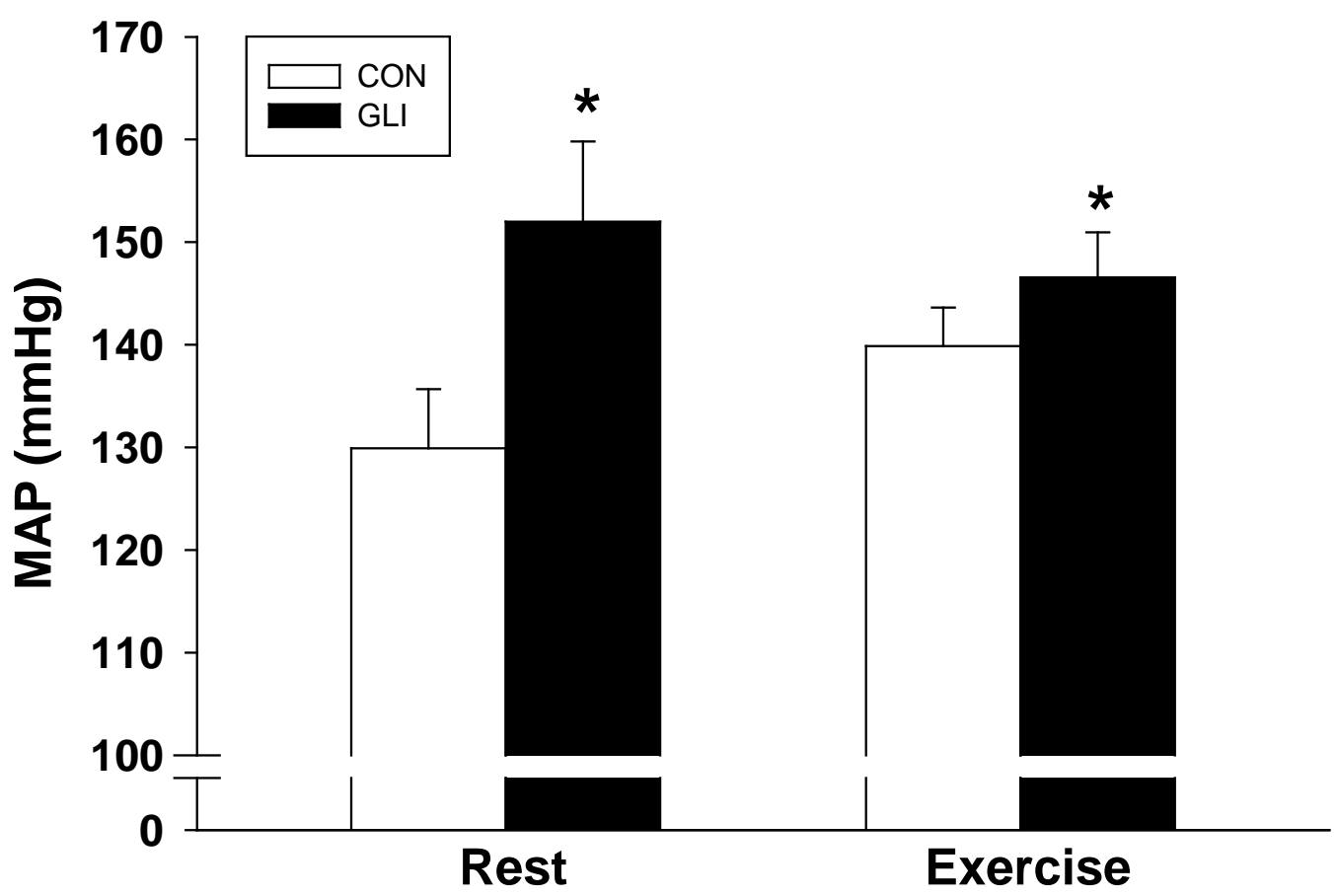

B.

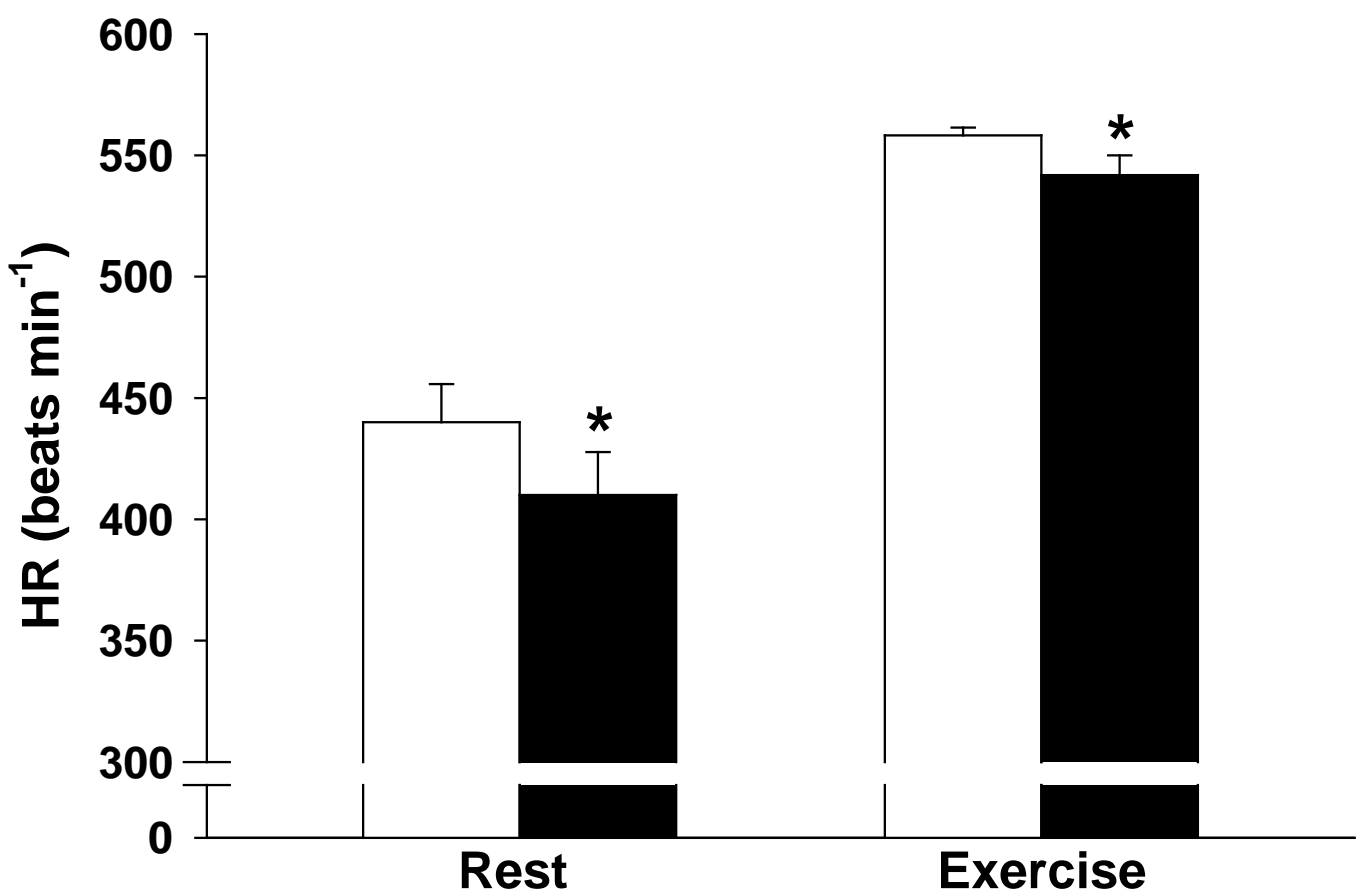

Figure 1. GLI increased MAP (A) and decreased $H R(B)$ at rest and during exercise compared to $\mathrm{CON}$. ${ }^{*}, \mathrm{P}<0.05$ versus control. 
Figure 2

A.

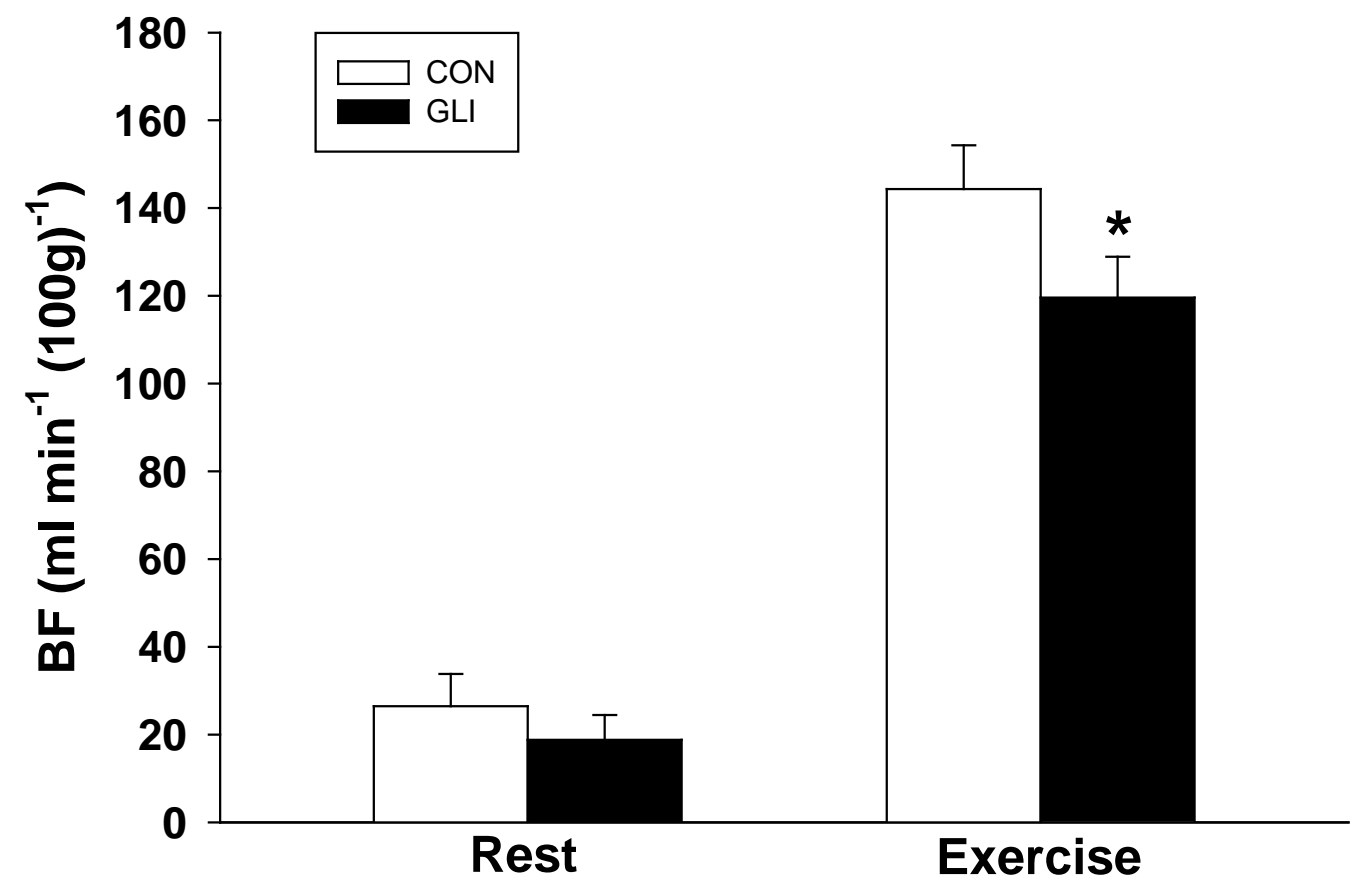

B.

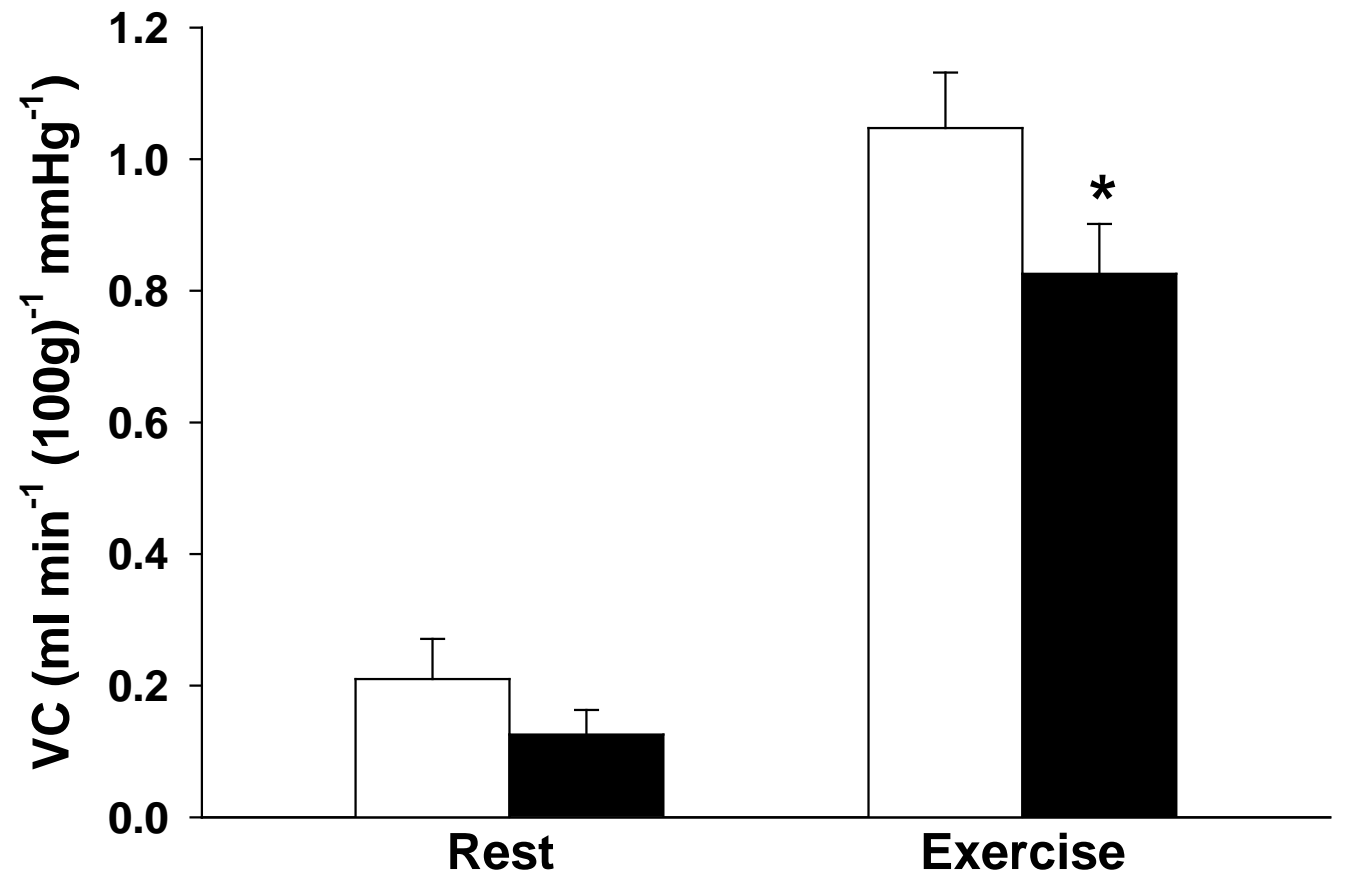

Figure 2. GLI decreased total hindlimb skeletal muscle BF (A) and VC (B) during submaximal exercise but not at rest compared to CON. ${ }^{*}, \mathrm{P}$ $<0.05$ versus control. 


\section{Figure 3}

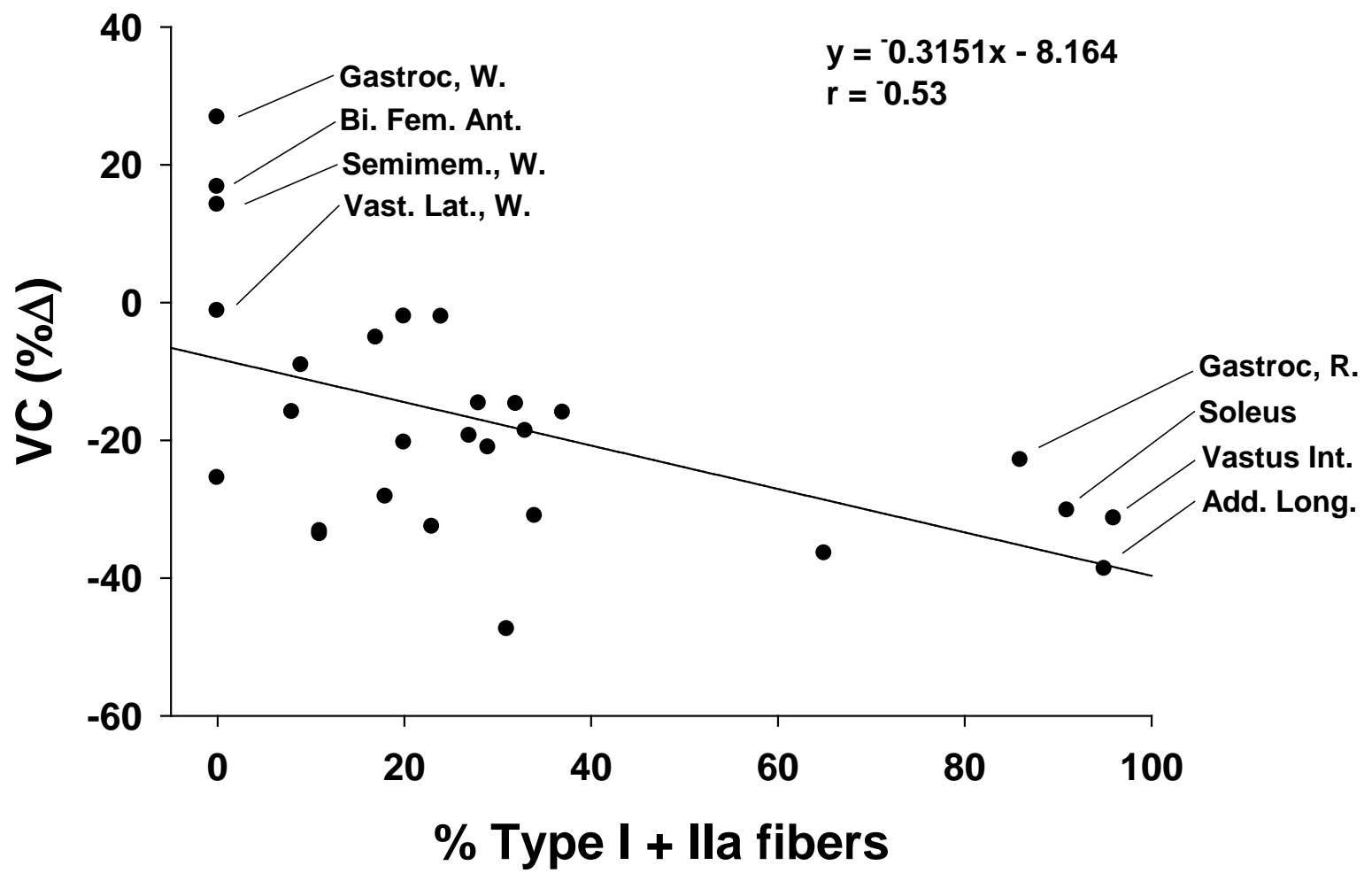

Figure 3. The percent decreases in hindlimb VC with GLI were positively correlated with the percent type I and type lla fibres of the muscles or muscle portions. $\mathrm{P}<0.05$. 
Figure 4

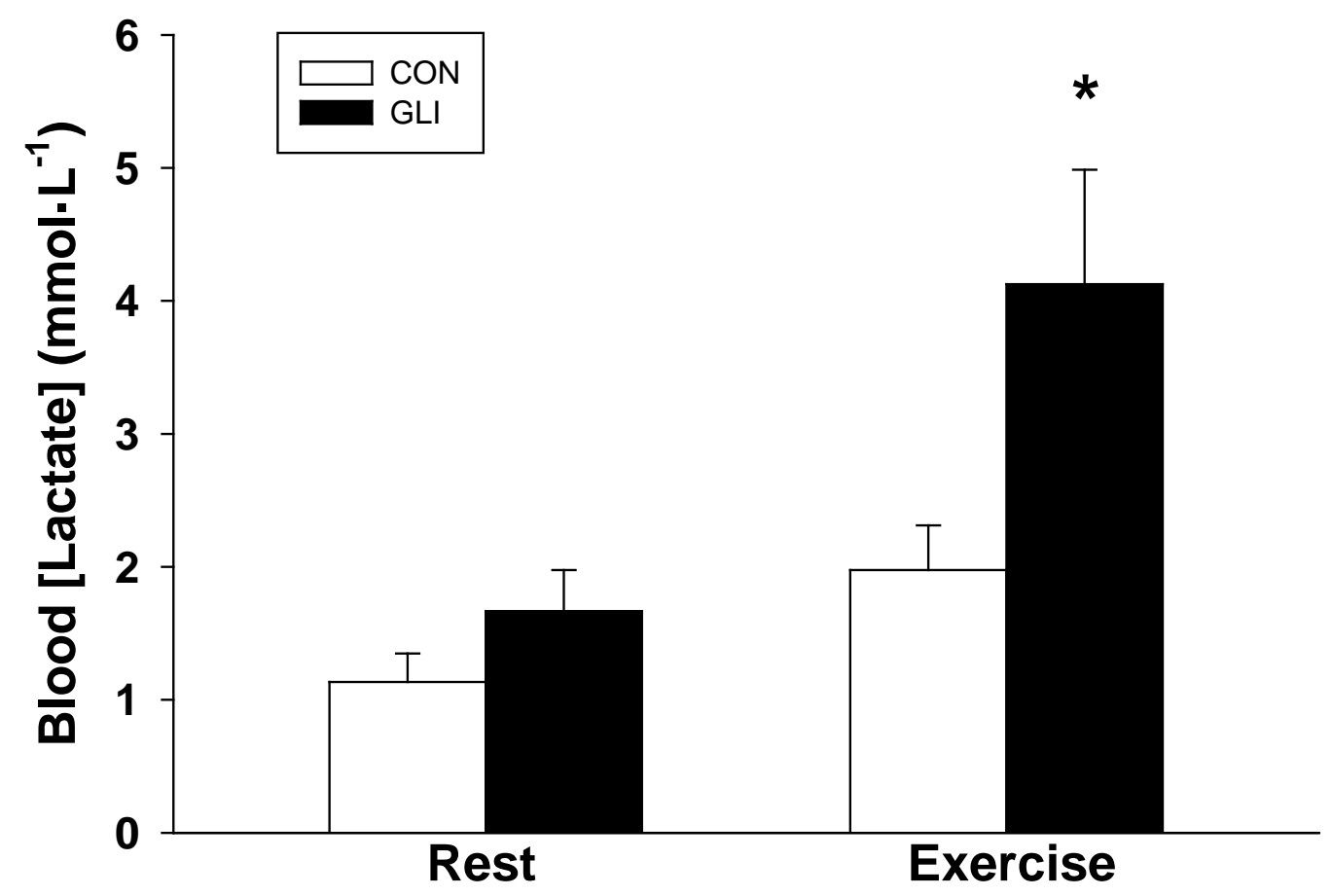

Figure 4. GLI increased blood [lactate] during submaximal exercise but not at rest compared to CON. ${ }^{*}, \mathrm{P}<0.05$ versus control. 